\title{
The hyperornithinemia-hyperammonemia- homocitrullinuria syndrome
}

\author{
Diego Martinelli ${ }^{1 \dagger}$, Daria Diodato ${ }^{2 \dagger}$, Emanuela Ponzi ${ }^{1,3 \dagger}$, Magnus Monné $^{4}$, Sara Boenzi ${ }^{1}$, Enrico Bertini ${ }^{2}$, \\ Giuseppe Fiermonte ${ }^{5}$ and Carlo Dionisi-Vici ${ }^{*}$
}

\begin{abstract}
Background: Hyperornithinemia-hyperammonemia-homocitrullinuria $(\mathrm{HHH})$ syndrome is a rare autosomal recessive disorder of the urea cycle. $\mathrm{HHH}$ has a panethnic distribution, with a major prevalence in Canada, Italy and Japan. Acute clinical signs include intermittent episodes of vomiting, confusion or coma and hepatitis-like attacks. Alternatively, patients show a chronic course with aversion for protein rich foods, developmental delay/intellectual disability, myoclonic seizures, ataxia and pyramidal dysfunction. HHH syndrome is caused by impaired ornithine transport across the inner mitochondrial membrane due to mutations in SLC25A15 gene, which encodes for the mitochondrial ornithine carrier ORC1. The diagnosis relies on clinical signs and the peculiar metabolic triad of hyperammonemia, hyperornithinemia, and urinary excretion of homocitrulline. $\mathrm{HHH}$ syndrome enters in the differential diagnosis with other inherited or acquired conditions presenting with hyperammonemia.
\end{abstract}

Methods: A systematic review of publications reporting patients with $\mathrm{HHH}$ syndrome was performed.

Results: We retrospectively evaluated the clinical, biochemical and genetic profile of $111 \mathrm{HHH}$ syndrome patients, 109 reported in 61 published articles, and two unpublished cases. Lethargy and coma are frequent at disease onset, whereas pyramidal dysfunction and cognitive/behavioural abnormalities represent the most common clinical features in late-onset cases or during the disease course. Two common mutations, F188del and R179* account respectively for about $30 \%$ and $15 \%$ of patients with the $\mathrm{HHH}$ syndrome. Interestingly, the majority of mutations are located in residues that have side chains protruding into the internal pore of ORC1, suggesting their possible interference with substrate translocation. Acute and chronic management consists in the control of hyperammonemia with protein-restricted diet supplemented with citrulline/arginine and ammonia scavengers. Prognosis of $\mathrm{HHH}$ syndrome is variable, ranging from a severe course with disabling manifestations to milder variants compatible with an almost normal life.

Conclusions: This paper provides detailed information on the clinical, metabolic and genetic profiles of all $\mathrm{HHH}$ syndrome patients published to date. The clinical phenotype is extremely variable and its severity does not correlate with the genotype or with recorded ammonium/ornithine plasma levels. Early intervention allows almost normal life span but the prognosis is variable, suggesting the need for a better understanding of the still unsolved pathophysiology of the disease.

Keywords: HHH syndrome, Urea cycle disorders, Hyperammonemia, SLC25A15, ORC1, ORNT1

\footnotetext{
* Correspondence: carlo.dionisivici@opbg.net

${ }^{\dagger}$ Equal contributors

'Division of Metabolism, Children Research Hospital Bambino Gesù, Rome, Italy

Full list of author information is available at the end of the article
} 


\section{Background}

Hyperornithinemia-hyperammonemia-homocitrullinuria ( $\mathrm{HHH}, \mathrm{MIM} \# 238970)$ syndrome is a rare genetic disorder of the urea cycle (UC) caused by mutations in the SLC25A15 or ORNT1 gene (MIM*603861), which encodes for the mitochondrial ornithine carrier ORC1 [1]. $\mathrm{HHH}$ syndrome represents a heterogeneous disease with high clinical variability, ranging from a mild form with learning difficulties and slight neurological involvement, to a more severe form with coma, lethargy, hepatic signs and seizures. Asides from the severe neonatal form, there is no evidence of a direct correlation between age of onset, which is variable, and disease severity [1]. As for other urea cycle disorders (UCDs), early diagnosis in infancy or childhood may improve the clinical outcome [1]. Acute treatment requires an emergency approach, whereas the long-term treatment consists of a lowprotein diet supplemented with citrulline or arginine; in some patients, sodium benzoate and/or sodium phenylbutyrate are used to maintain blood ammonia in a safe range [1]. In this paper, we aim to provide a comprehensive review of the genetic and molecular aspects of $\mathrm{HHH}$ syndrome, a descriptive picture of clinical features and therapeutic strategies along with a discussion on the still unsolved questions related to the disease pathomechanisms.

\section{History and disease definition}

In 1969, Shih et al. described a 3 years-old boy with cognitive impairment and myoclonic seizures, in whom intermittent hyperammonemia was associated with abnormal high plasma ornithine levels and homocitrullinuria [2]. These authors coined the name "hyperornithinemiahyperammonemia-homocitrullinuria ( $\mathrm{HHH}$ ) syndrome" (Orpha number 415) to describe the peculiar biochemical profile, suggestive of a "block in the ornithine metabolic pathway".

\section{Epidemiology}

Since the original description [2-4], more than 100 patients with $\mathrm{HHH}$ syndrome have been reported [5-61]. Overall, according to a recent survey based on newborn screening data on over 6 million births in United States (US) and data from two large US and European longitudinal registries, the incidence of all UCDs is estimated as 1:35.000 live births [62]; however figures reporting the incidence of $\mathrm{HHH}$ syndrome are still lacking. Based on the few available large series studies on UCDs, HHH syndrome accounts for $1 \%-3,8 \%$ of all UCDs $[62,63]$. On the basis of the available information in the literature for 97 out of 111 patients [5-61] the male/female ratio is approximately 2:1 (Table 1).

\section{Methods}

We retrieved clinical and investigational data on $\mathrm{HHH}$ syndrome patients published to date. The PubMed database was searched using the terms: "HHH syndrome; Hyperornithinemia; Hyperammonemia; Homocitrullinuria; ornithine carrier; ORC1; ORNT1; urea cycle disorders; SLC25A15". The terms were variably combined with: "early onset, infancy-childhood onset; adult onset, late onset, review, case, case series". In addition, references listed in the papers retrieved by this method as well as in the textbook "The Metabolic and Molecular Bases of Inherited Diseases" [64] were screened, along with a reference list started in 1985 by the last author of this work. Data on clinical symptoms and biochemical and genetic data were pooled for analysis whenever the description of the cases allowed. The individual relevant data obtained from the literature were used to create a database that is reported in Table 1 and in Additional file 1: Table S1. We additionally included data from two unreported patients, recently diagnosed and managed at Children's Research Hospital Bambino Gesù, Rome, Italy (patients 110 and 111); written informed consent was obtained from the caregivers of these two patients for publication of their clinical and biochemical data. Patients n. 10, 19, 25, 49, 51, 52, and 94 were monitored longitudinally in the same institution.

\section{Results}

\section{Ethnic distribution}

Although the disease has a panethnic distribution, it has been more frequently reported in three countries: 25 patients (23\%) were Canadian, as a result of a founder mutation in Quebec [37], 18 patients (17\%) were Italian and 14 patients $(13 \%)$ were Japanese. Therefore, these three countries account for more of $50 \%$ of affected cases. The complete list of patients' ethnic background is displayed in Table 1.

\section{Clinical description}

Age at onset, type and severity of the symptoms in $\mathrm{HHH}$ syndrome are highly variable. Clinical symptoms usually start from early infancy, including the neonatal period, to childhood and, more rarely, in adulthood.

\section{Age at onset and diagnosis}

The retrospective review of the literature provided information on the age at onset in $54 \mathrm{HHH}$ syndrome patients and on the age at diagnosis in 105 subjects (Table 1), whom we arbitrarily divided into four categories: neonatal (birth -1 month), infantile ( $>1$ month -1 year), childhood ( $>1$ years -12 years), and adolescence/adulthood ( $>12$ years). In 14 patients there was a prospective diagnosis, because of an affected sibling or previous familial $\mathrm{HHH}$ syndrome cases; only one patient was identified by newborn screening. Figure 1 shows the percentage of patients grouped into the four categories at onset and at diagnosis, respectively. As shown in the 
Table 1 The table summarizes relevant clinical features and molecular findings in 111 patients with HHH syndrome

\begin{tabular}{|c|c|c|c|c|c|c|c|c|c|c|c|c|c|c|c|}
\hline $\mathrm{Pt}$ & Sex & Ethnicity & $\begin{array}{l}\text { Onset } \\
\text { years }\end{array}$ & $\begin{array}{l}\text { Diagnosis } \\
\text { years }\end{array}$ & $\begin{array}{l}\text { Vital status } \\
\text { (last age } \\
\text { reported) }\end{array}$ & Lethargy & Coma & $\begin{array}{l}\Uparrow \text { ASAT } \\
\Uparrow \text { ALAT }\end{array}$ & Coagulopathy & $\begin{array}{l}\text { Intellectual } \\
\text { disability }\end{array}$ & $\begin{array}{l}\text { Seizures, } \\
\text { myoclonic }\end{array}$ & $\begin{array}{l}\text { Pyramidal } \\
\text { signs }\end{array}$ & $\begin{array}{l}\text { Plasma } \\
\text { ornithine at } \\
\text { diagnosis }\end{array}$ & $\begin{array}{l}\text { Mutation effect } \\
\text { at protein level }\end{array}$ & Ref. \\
\hline 1 & $m$ & $\begin{array}{l}\text { English/ } \\
\text { French } \\
\text { Canadian }\end{array}$ & 1,1 & 1,5 & 43,0 & Yes & No & Yes & No & 1 & Yes & Yes & 915 & p.A264P/p.F188del & {$[2-4]$} \\
\hline 2 & $f$ & English & 2,5 & 21,0 & 23,0 & Yes & Yes & No & No & 3 & Yes & Yes & 1021 & & {$[5,6]$} \\
\hline 3 & m & $\begin{array}{l}\text { French } \\
\text { Canadian }\end{array}$ & 0,8 & 7,0 & 9,0 & Yes & Yes & Yes & Yes & 3 & Yes & Yes & 372 & & {$[7-12]$} \\
\hline 4 & $\mathrm{~m}$ & $\begin{array}{l}\text { French } \\
\text { Canadian }\end{array}$ & 1,9 & 2,0 & 5,0 & Yes & Yes & & & 3 & Yes & Yes & 330 & & {$[7,9,11]$} \\
\hline 5 & f & $\begin{array}{l}\text { French } \\
\text { Canadian }\end{array}$ & & 47 & 17,0 & Yes & No & & & 1 & No & No & 380 & & {$[7,11]$} \\
\hline 6 & $\mathrm{~m}$ & $\begin{array}{l}\text { French } \\
\text { Canadian }\end{array}$ & & $31,0^{*}$ & 31,0 & No & No & & & 3 & Yes & & 519 & & {$[7]$} \\
\hline 7 & f & $\begin{array}{l}\text { French } \\
\text { Canadian }\end{array}$ & & $22,0^{*}$ & 22,0 & yes & No & & & No & No & No & 430 & & [7] \\
\hline 8 & $\mathrm{~m}$ & $\begin{array}{l}\text { French } \\
\text { Canadian }\end{array}$ & & $18,0^{*}$ & 19,0 & No & No & & Yest & 3 & No & No & 483 & & {$[7]$} \\
\hline 9 & $f$ & NA & & 4,0 & 6,5 & No & No & Yes & No & No & No & No & 410 & & [13] \\
\hline 10 & f & Italian & 0,2 & 0,8 & 1,0 & Yes & & No & No & 1 & Yes & Yes & 689 & & [14] \\
\hline 11 & m & NA & 1,4 & 2,5 & 4,7 & Yes & No & No & & 3 & Yes & No & 229 & & [9] \\
\hline 12 & m & Italian & 1,1 & 2,5 & Death 2,5 & Yes & Yes & Yes+ & Yes+ & & & Yes & 797 & & [15] \\
\hline 13 & m & Italian & 0,8 & 2,6 & 3,6 & Yes & & No & No & No & & Yes & 1041 & & {$[15]$} \\
\hline 14 & m & Japanese & & 42,0 & 46,0 & Yes & Yes & No & & & & & 700 & & [16] \\
\hline 15 & m & NA & & 5,5 & 8,0 & No & No & No & No & 3 & Yes & Yes & 586 & & [17] \\
\hline 16 & $\mathrm{~m}$ & NA & & & & & & & & No & & & 1014 & & [18] \\
\hline 17 & m & NA & & 4,2 & 10,7 & & & & & 1 & & & & & [18] \\
\hline 18 & m & $\begin{array}{l}\text { Norwegian/ } \\
\text { Yugosl-Italian }\end{array}$ & 0,4 & 1,1 & 4,0 & No & No & Yest & Yes & No & No & No & 887 & & [19] \\
\hline 19 & f & Italian & Birth & 0,2 & 20,0 & Yes & Yes & Yes & Yes & No & No & Yes & 618 & p.G27R/p.G27R & {$[20-23]$} \\
\hline 20 & m & Japanese & & $13,0^{*}$ & 13,0 & No & No & No & No & 1 & Yes & Yes & 409 & & [24] \\
\hline 21 & $m$ & Japanese & 4,0 & 19,0 & 19,0 & Yes & No & No & No & 3 & Yes & Yes & 477 & & [24] \\
\hline 22 & $\mathrm{~m}$ & Spanish & 9,0 & 21,0 & 21,0 & & No & No & & 3 & No & Yes & 719 & & [25] \\
\hline 23 & f & Spanish & & 18,0 & 18,0 & & No & No & & 3 & No & Yes & 780 & & [25] \\
\hline 24 & $\mathrm{~m}$ & Spanish & 4,0 & 10,0 & 13,0 & Yes & Yes & No & NA & 3 & & Yes & 713 & & [25] \\
\hline
\end{tabular}


Table 1 The table summarizes relevant clinical features and molecular findings in 111 patients with HHH syndrome (Continued)

\begin{tabular}{|c|c|c|c|c|c|c|c|c|c|c|c|c|c|c|c|}
\hline 25 & $m$ & Italian & Birth & 2,0 & 21,0 & Yes & Yes & Yes & No & 3 & Yes & Yes & & p.Ser90*/p.Ser90* & {$[21-23]$} \\
\hline 26 & $\mathrm{~m}$ & Japanese & 3,0 & 10,0 & 10,0 & Yes & No & No & No & 3 & No & Yes & 419 & p.R179*/p.R179* & {$[26,27]$} \\
\hline 27 & $f$ & Japanese & & & 37,0 & & & & & & & & 504 & & {$[28]$} \\
\hline 28 & $\mathrm{~m}$ & Japanese & & & 11,0 & & & & & & & & 879 & & [28] \\
\hline 29 & $\mathrm{~m}$ & Japanese & & & 19,0 & & & & & & & & 553 & & [28] \\
\hline 30 & $f$ & & & 20,0 & 24,0 & & & & & & Yes & Yes & 860 & & [29] \\
\hline 31 & $\mathrm{~m}$ & Japanese & & 17,0 & 17,0 & Yes & No & & & 3 & Yes & Yes & 834 & $\begin{array}{l}\text { p.229_230insN/ } \\
\text { p.229_230insN }\end{array}$ & {$[30,31]$} \\
\hline 32 & $\mathrm{~m}$ & & & 37,0 & 39,0 & Yes & Yes & Yes & Yes & No & No & Yes & 310 & & [32] \\
\hline 33 & f & & & $40,0^{*}$ & 42,0 & Yes & No & & & No & & & 263 & & {$[32]$} \\
\hline 34 & $\mathrm{~m}$ & Japanese & & 35,0 & 41,0 & Yes & Yes & No & & 1 & No & Yes & 586 & p.R179*/p.R179* & {$[31,33]$} \\
\hline 35 & $\mathrm{~m}$ & Japanese & & 15,0 & 16,0 & & No & No & & 3 & No & Yes & & p.G27E/p.G27E & {$[31,34]$} \\
\hline 36 & $\mathrm{~m}$ & $\begin{array}{l}\text { French } \\
\text { Canadian }\end{array}$ & Birth & Birth & Death Birth & Yes & Yes & Yes & & & & & 1915 & & {$[35]$} \\
\hline 37 & $\mathrm{~m}$ & $\begin{array}{l}\text { French } \\
\text { Canadian }\end{array}$ & & 1,2 & 21,0 & No & No & Yes & Yes & 1 & No & Yes & 727 & p.F188del/p.F188del & {$[36-38]$} \\
\hline 38 & $f$ & $\begin{array}{l}\text { French } \\
\text { Canadian }\end{array}$ & & 5,3 & 22,0 & No & No & Yes & Yes & 1 & No & Yes & 343 & p.F188del & {$[36-38]$} \\
\hline 39 & $f$ & $\begin{array}{l}\text { French } \\
\text { Canadian }\end{array}$ & & 1,3 & 25,0 & No & No & Yes & Yes & 1 & No & Yes & 1083 & p.F188del/p.F188del & {$[36-38]$} \\
\hline 40 & $\mathrm{~m}$ & $\begin{array}{l}\text { French } \\
\text { Canadian }\end{array}$ & & 12,0 & 33,0 & No & No & No & No & 3 & No & Yes & 515 & p.F188del/p.F188del & {$[36-38]$} \\
\hline 41 & $\mathrm{~m}$ & $\begin{array}{l}\text { French } \\
\text { Canadian }\end{array}$ & & 3,5 & 35,0 & No & No & Yes+ & No & 3 & No & Yes & 606 & p.F188del/p.F188del & {$[36-38]$} \\
\hline 42 & $\mathrm{~m}$ & $\begin{array}{l}\text { French } \\
\text { Canadian }\end{array}$ & & 8,0 & 40,0 & Yes & Yes & Yes & Yes+ & 3 & Yes & Yes & 700 & p.F188del/p.F188del & {$[36-39]$} \\
\hline 43 & $f$ & $\begin{array}{l}\text { French } \\
\text { Canadian }\end{array}$ & 3,5 & 5,5 & 6,5 & No & No & Yes & Yes & 1 & No & Yes & 470 & & {$[40]$} \\
\hline 44 & & NA & 0,6 & 0,6 & & & & & & 3 & & & 577 & & [41] \\
\hline 45 & $\mathrm{~m}$ & Italian & Birth & Birth & 10,0 & Yes & Yes & No & No & No & Yes & Yes & 595 & p.G27R/p.Tyr55 & {$[22,23,42]$} \\
\hline 46 & & $\begin{array}{l}\text { Japanese/ } \\
\text { Irish }\end{array}$ & & & & & & & & & & & & p.E180K/large del & [37] \\
\hline 47 & & Palestinian & Birth & Birth & & Yes & Yes & & & & & & & p.A15E/p.A15E & {$[38,43]$} \\
\hline 48 & $f$ & $\begin{array}{l}\text { South } \\
\text { American }\end{array}$ & & & & & & & & & & & & p.M33QfsX1/p.M33QfsX1 & {$[38,43]$} \\
\hline
\end{tabular}


Table 1 The table summarizes relevant clinical features and molecular findings in $\mathbf{1 1 1}$ patients with HHH syndrome (Continued)

\begin{tabular}{|c|c|c|c|c|c|c|c|c|c|c|c|c|c|c|c|}
\hline 49 & $m$ & Italian & 12,0 & 26,0 & 28,0 & Yes & No & No & Yes & 1 & Yes & Yes & & p.R179*/p.R179* & {$[22,23]$} \\
\hline 50 & m & Italian & 18,0 & 21,0 & 29,0 & Yes & Yes & Yest & No & 1 & Yes & Yes & 505 & $\begin{array}{l}\text { (IVS5 }+1 \mathrm{~g}>\text { a/IVS5 }+ \\
1 \mathrm{~g}>\mathrm{a}) \text { exon skipping }\end{array}$ & {$[22,23]$} \\
\hline 51 & f & Italian & 3,0 & 7,0 & 24,0 & Yes & Yes & No & No & 2 & Yes & Yes & 780 & p.R275Q/p.R275Q & {$[22,23,44]$} \\
\hline 52 & f & Italian & 1,0 & 33,0 & 44,0 & & & & & 3 & & Yes & & p.Q89*/p.Q89* & {$[22,23]$} \\
\hline 53 & m & Italian & Birth & Birth & 23,0 & Yes & Yes & & & No & Yes & Yes & & p.F188del/p.G190D & {$[22,23]$} \\
\hline 54 & f & NA & 5,0 & 17,0 & 32,5 & & No & No & No & 3 & No & Yes & 312 & & {$[45]$} \\
\hline 55 & m & NA & 13,0 & 15,0 & 15,0 & & No & No & & 3 & No & & 520 & & {$[45]$} \\
\hline 56 & $f$ & NA & & 0,8 & 0,8 & & No & No & No & 1 & No & No & & & {$[46]$} \\
\hline 57 & f & Japanese & & 52,0 & 52,0 & No & No & No & No & No & Yes & Yes & 373 & p.R179*/p.R179* & {$[27,47]$} \\
\hline 58 & m & Slovakian & & 1,6 & 10,0 & No & No & Yes+ & & No & No & & 425 & p.G113C & {$[48]$} \\
\hline 59 & $\mathrm{~m}$ & Japanese & 1,5 & 15,0 & 15,0 & & No & No & No & 3 & No & Yes & 682 & p.P126R/p.P126R & [49] \\
\hline 60 & m & Palestinian & & 1,8 & 1,8 & & No & Yes & No & 3 & Yes & No & 532 & p.L193*/p.L193* & {$[50]$} \\
\hline 61 & m & Palestinian & & $13,0^{*}$ & 13,0 & & No & No & No & 3 & Yes & No & 314 & p.L193*/p.L193* & {$[50]$} \\
\hline 62 & f & Japanese & 2,0 & 30,0 & 30,0 & & No & & & 2 & Yes & Yes & 373 & p.R275*/p.R275* & [51] \\
\hline 63 & $\mathrm{~m}$ & Japanese & 3,0 & 34,0 & Death 34,0 & Yes & Yes & & & 3 & Yes & Yes & & p.R275*/p.R275* & [51] \\
\hline 64 & $\mathrm{~m}$ & Italian & 3,5 & 3,5 & 3,5 & Yes & No & Yest & Yes+ & No & No & No & 852 & p.G113C/p.M273K & {$[52]$} \\
\hline 65 & $\mathrm{~m}$ & Mexican & & $5,0^{*}$ & 9,0 & & No & Yes+ & Yes & No & No & No & 697 & p.T32R/p.T32R & [53] \\
\hline 66 & $f$ & Mexican & & 13,0 & 18,0 & & No & & & No & No & No & 353 & p.T32R/p.T32R & [53] \\
\hline 67 & $\mathrm{~m}$ & Mexican & & 8,0 & Death 21,0 & Yes & Yes & & & 3 & No & Yes & 386 & p.T32R/p.T32R & {$[53]$} \\
\hline 68 & $\mathrm{~m}$ & Mexican & & $7,0^{*}$ & 20,0 & & No & & & No & No & No & 371 & p.T32R/p.T32R & {$[53]$} \\
\hline 69 & $\mathrm{~m}$ & Mexican & & $3,0^{*}$ & 15,0 & & No & & & No & No & No & 370 & p.T32R/p.T32R & {$[53]$} \\
\hline 70 & $\mathrm{~m}$ & NA & Birth & 0,1 & 3,0 & & Yes & & & 3 & & & 616 & & {$[54]$} \\
\hline 71 & $f$ & $\begin{array}{l}\text { French- } \\
\text { Canadian }\end{array}$ & 1,0 & 1,1 & 1,1 & Yes & No & Yes+ & Yes+ & No & No & No & 933 & p.F188del/p.F188del & {$[55]$} \\
\hline 72 & $f$ & $\begin{array}{l}\text { French- } \\
\text { Canadian }\end{array}$ & 1,2 & 1,2 & 1,2 & No & No & Yes+ & Yes+ & No & No & No & 580 & p.F188del/p.F188del & [55] \\
\hline 73 & $f$ & Saudi arabia & 1,0 & 1,5 & 4,0 & No & No & Yes+ & Yes+ & 3 & No & Yes & 465 & p.G220R/p.G220R & {$[56]$} \\
\hline 74 & & Saudi arabia & & $13,0^{*}$ & 13,0 & No & No & & & 1 & No & Yes & 590 & p.G220R/p.G220R & {$[56]$} \\
\hline 75 & & Saudi arabia & & $7.0^{*}$ & 7,0 & No & No & & & 1 & No & Yes & 493 & p.G220R/p.G220R & {$[56]$} \\
\hline 76 & & $\begin{array}{l}\text { French } \\
\text { Canadian }\end{array}$ & & 1,0 & 14,0 & No & No & Yest & Yes+ & & No & Yes & 642 & p.F188del/p.F188del & {$[38]$} \\
\hline 77 & & $\begin{array}{l}\text { French } \\
\text { Canadian }\end{array}$ & & 3,6 & 13,0 & No & No & Yest & Yes & & No & Yes & 432 & p.F188del/p.F188del & {$[38]$} \\
\hline
\end{tabular}


Table 1 The table summarizes relevant clinical features and molecular findings in $\mathbf{1 1 1}$ patients with HHH syndrome (Continued)

\begin{tabular}{|c|c|c|c|c|c|c|c|c|c|c|c|c|c|c|c|}
\hline 78 & & $\begin{array}{l}\text { French } \\
\text { Canadian }\end{array}$ & & 2,4 & 9,0 & No & No & Yes+ & Yes+ & & No & Yes & 310 & p.F188del/p.F188del & [38] \\
\hline 79 & & $\begin{array}{l}\text { French } \\
\text { Canadian }\end{array}$ & & $0,2^{* *}$ & 7,0 & No & No & No & No & & No & Yes & 397 & p.F188del/p.F188del & {$[38]$} \\
\hline 80 & & $\begin{array}{l}\text { French } \\
\text { Canadian }\end{array}$ & & 2,0 & 6,0 & No & No & Yes & No & & No & Yes & 337 & p.F188del/p.F188del & [38] \\
\hline 81 & & $\begin{array}{l}\text { French } \\
\text { Canadian }\end{array}$ & & 15,0 & 29,0 & Yes & Yes & No & Yes & & Yes & Yes & 431 & p.F188del/p.F188del & {$[38]$} \\
\hline 82 & & $\begin{array}{l}\text { French } \\
\text { Canadian }\end{array}$ & & 16,0 & Death 23,0 & Yes & Yes & Yes & & & No & Yes & 227 & p.F188del/p.F188del & [38] \\
\hline 83 & & $\begin{array}{l}\text { French } \\
\text { Canadian }\end{array}$ & & 2,0 & 31,0 & No & No & & & & No & Yes & 581 & p.F188del/p.F188del & [38] \\
\hline 84 & & $\begin{array}{l}\text { French } \\
\text { Canadian }\end{array}$ & & 3,0 & 17,0 & No & No & & & & No & Yes & 529 & p.F188del/p.F188del & {$[38]$} \\
\hline 85 & & $\begin{array}{l}\text { French } \\
\text { Canadian }\end{array}$ & & 1,5 & 5,0 & No & No & Yes & & & No & Yes & 348 & p.F188del/p.F188del & [38] \\
\hline 86 & $\mathrm{~m}$ & Belgium & 0,3 & 0,7 & 6,0 & No & No & Yes & Yes & 1 & No & No & 951 & p.M37R/p.M37R & {$[57]$} \\
\hline 87 & $f$ & Italian & Birth & 0,2 & Death 0,2 & & Yes & No & No & No & No & No & & p.L71Q/p.L71Q & {$[57]$} \\
\hline 88 & $\mathrm{~m}$ & Algerian & & 2,0 & 5,0 & & No & No & No & 3 & No & Yes & 885 & p.K245*/p.K245* & {$[57]$} \\
\hline 89 & $\mathrm{~m}$ & Algerian & Birth & Birth* & 3,0 & & No & No & No & 3 & No & Yes & 887 & p.K245*/p.K245* & [57] \\
\hline 90 & $f$ & Senegal & Birth & Birth & 6,0 & Yes & Yes & No & Yes+ & 1 & Yes & Yes & 509 & p.R179*/p.R179* & {$[57]$} \\
\hline 91 & $f$ & Senegal & Birth & Birth & 6,0 & Yes & No & No & No & 1 & No & Yes & 290 & p.R179*/p.R179* & [57] \\
\hline 92 & $\mathrm{~m}$ & Spanish & & 2,0 & 2,0 & & & & & 3 & & & 419 & p.G216S/p.G216S & {$[57]$} \\
\hline 93 & $f$ & Taiwan & 1,1 & 2,0 & 2,0 & Yes & Yes & Yes+ & Yes+ & & & & 450 & p.T2721/p.T2721 & {$[57]$} \\
\hline 94 & $\mathrm{~m}$ & Italian & & 41,0 & 41,0 & Yes & Yes & No & Yes & No & No & Yes & 216 & p.G27R/p.G27R & {$[57]$} \\
\hline 95 & $\mathrm{~m}$ & Italian & 24,0 & 54,0 & 54,0 & Yes & No & Yes+ & Yes & No & No & Yes & 603 & $\begin{array}{l}\text { (c.56+1G > T/intronic } \\
\text { change) exon skipping }\end{array}$ & {$[57]$} \\
\hline 96 & $f$ & USA-Greece & Birth & Birth & 0,1 & Yes & Yes & No & Yes & No & & & 370 & p.S175fsX192/p.L283F & {$[57]$} \\
\hline 97 & $\mathrm{~m}$ & Morocco & & 1,2 & 1,5 & & Yes & Yest & Yest & 1 & No & Yes & 700 & p.A70L/p.A70L & {$[57]$} \\
\hline 98 & $f$ & Pakistan & & 1,0 & 5,0 & No & No & Yes & No & 3 & No & No & 471 & p.F188L/p.F188L & {$[57]$} \\
\hline 99 & $\mathrm{~m}$ & Morocco & 1,7 & 1,7 & 2,0 & Yes & No & Yes+ & Yes & No & No & No & 493 & p.R179*/p.R179* & {$[57]$} \\
\hline 100 & $\mathrm{~m}$ & Morocco & & $4,0^{*}$ & 4,0 & & & & & & & & & p.R179*/p.R179* & [57] \\
\hline 101 & $f$ & Pakistan & 20,0 & 57,0 & 57,0 & Yes & Yes & No & No & No & Yes & Yes & & p.A70L/p.A70L & {$[57]$} \\
\hline 102 & $\mathrm{~m}$ & Indian & 35,0 & 35,0 & 35,0 & Yes & & No & No & No & & No & 292 & p.G220R/p.R275* & [58] \\
\hline
\end{tabular}


Table 1 The table summarizes relevant clinical features and molecular findings in $\mathbf{1 1 1}$ patients with HHH syndrome (Continued)

\begin{tabular}{|c|c|c|c|c|c|c|c|c|c|c|c|c|c|c|c|}
\hline 103 & $\mathrm{f}$ & $\begin{array}{l}\text { French } \\
\text { Canadian }\end{array}$ & 2,0 & 15,0 & 57,0 & Yes & Yes & Yes & & & Yes & Yes & 542 & p.F188del/p.A264P & [4] \\
\hline 104 & $f$ & El Salvador & 4,4 & 4,5 & Death 31,0 & Yes & No & Yes+ & Yes & 2 & Yes & Yes & 521 & p.M33Qfs*1/M33Qfs*1 & [4] \\
\hline 105 & $f$ & Vietnam & 1,0 & 5,0 & 29,0 & Yes & Yes & Yes & Yes & 2 & Yes & Yes & 1439 & p.R179*/p.R179* & [4] \\
\hline 106 & $\mathrm{~m}$ & Italian & 6,0 & 36,0 & 36,0 & Yes & & & & & & Yes & 309 & p.F188del/p.L193P & [59] \\
\hline 107 & $\mathrm{~m}$ & Turkish & 3,5 & 6,0 & 9,0 & Yes & No & No & No & & No & & 380 & p.A15V/p.A15V & {$[60]$} \\
\hline 108 & $\mathrm{~m}$ & Han Chinese & 1,0 & 2,0 & 6,0 & No & No & Yes & Yes & No & No & No & 503 & p.R179*/p.T272l & [61] \\
\hline 109 & $\mathrm{~m}$ & Han Chinese & & Birth* & 3,0 & No & No & No & No & No & No & No & & p.R179*/p.T2721 & [61] \\
\hline 110 & $f$ & Italian & 1,0 & 8,0 & 8,0 & No & No & Yes & No & 1 & No & Yes & 427 & p.G27R/p.R275G & Unp. \\
\hline 111 & $f$ & Italian & 1,0 & $4,0^{*}$ & 4,0 & No & No & No & No & No & No & Yes & 531 & p.G27R/p.R275G & Unp. \\
\hline
\end{tabular}

Yes + means severe abnormality; age at diagnosis includes *prospective diagnosis and **newborn screening; intellectual disability (score: 1, mild; 2, moderate; 3, severe); Unp. means unpublished; $\Uparrow$ means increased. 


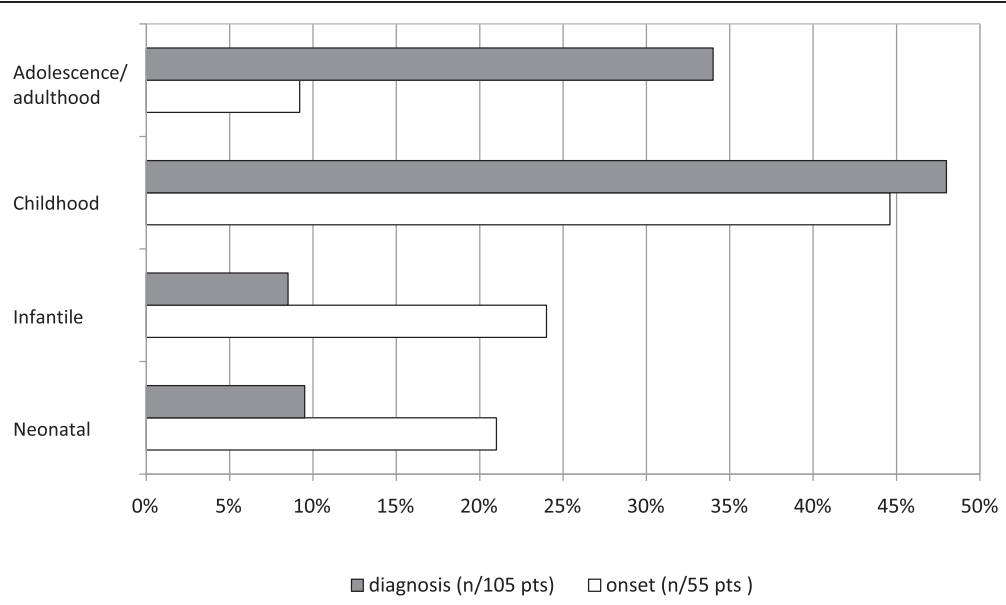

Figure 1 The graph shows the age at onset (white bars) and the age at diagnosis (gray bars) of HHH syndrome patients. Patients are divided into four age categories: neonatal (birth -1 month) infantile (> 1 month -1 year), childhood (> 1 years -12 yrs), and adolescence/ adulthood (> 12 years). Values are expressed as percentage of the total.

figure, $22 \%$ had a neonatal presentation, $24 \%$ infantile, $44 \%$ manifested the disorder in childhood, and 9\% in adolescence/adulthood. Although symptoms began most frequently in neonatal age/infancy (46\% of patients), the diagnosis was often delayed with at least one fourth of cases identified in adulthood. Remarkably, in one third of patients with neonatal onset of symptoms, the diagnosis was delayed into subsequent diagnostic age categories. By comparing the age at onset of the clinical symptoms with the age of diagnosis for those cases in which both these data were available, there was a mean diagnostic delay of $6.3 \pm 10.1$ years (range $0-$ 37 years).

\section{Acute presentation}

As seen in other UCDs [1], in the acute phase the $\mathrm{HHH}$ syndrome combines hyperammonemia with tachypnoea, respiratory alkalosis, feeding and gastrointestinal problems, ataxia, lethargy, confusion, and coma. About $1 / 3$ of patients experienced an overt episode of coma and many others had recurrent episodes of lethargy (Figure 2). Coma and lethargy at onset are quite common in the earlier onset group (about 70\%), becoming progressively less frequent in patients with later onset. Variable neurological symptoms may characterize the acute presentation and include seizures, dysphasia, movement and gait disturbances, drop-attacks and behavioural changes $[38,57,58]$.

As shown in Figure 2, HHH syndrome may also exhibit as fulminant liver failure with severe coagulation abnormalities (e.g. subdural hematoma, gingival bleeding, melena) and/or as hepatitis-like attacks [15,23, $25,35,37,38,50,52,57]$. Remarkably, in some cases massive elevation of transaminases, with or without signs of acute liver failure (i.e. coagulation abnormalities with prolonged prothombin time), occurred in the absence of overt hyperammonemia $[15,38,53,55,57]$.

\section{Chronic presentation}

HHH syndrome may also present a more chronic and slowly progressive course, characterized by an aversion to protein-rich foods, progressive encephalopathy with mental regression and signs of motor dysfunction (Figure 2). Affected patients in the late-onset categories come to medical attention mainly for evaluation of intellectual disability (ID), recurrent vomiting or neurological findings like ataxia and seizures.

\section{Neurological complications}

The peculiar feature of $\mathrm{HHH}$ syndrome is a progressive neurological dysfunction characterized by pyramidal tract signs with spastic gait, associated with cerebellar symptoms and myoclonic seizures [23,36,38]. Regardless of the age and type of onset, pyramidal dysfunction has been reported in about 2/3 of patients (Figure 2). This feature can vary from lower limb hyperreflexia with positive Babinski sign, with or without gait abnormalities, to a clear picture of spastic paraparesis. Cerebellar signs include ataxia, poor hand and fine motor coordination, dysdiadochokinesia, dysarthria, nystagmus and intentional tremor $[4,23,36,38]$. Other neurological signs include muscle weakness, involuntary hand movements, buccofaciolingual dyspraxia and psychiatric disorders. Seizures, mainly myoclonic, are present in $35 \%$ of patients (Figure 2) and seem to be more frequent in those with an earlier onset of the disease $[4,14,51,59]$.

Cognitive impairment is also often reported in this disorder, and may range from major developmental delay to variable degree of ID $[23,36,38]$. Independently from the age of onset, a greater proportion of patients $(74 \%)$ 


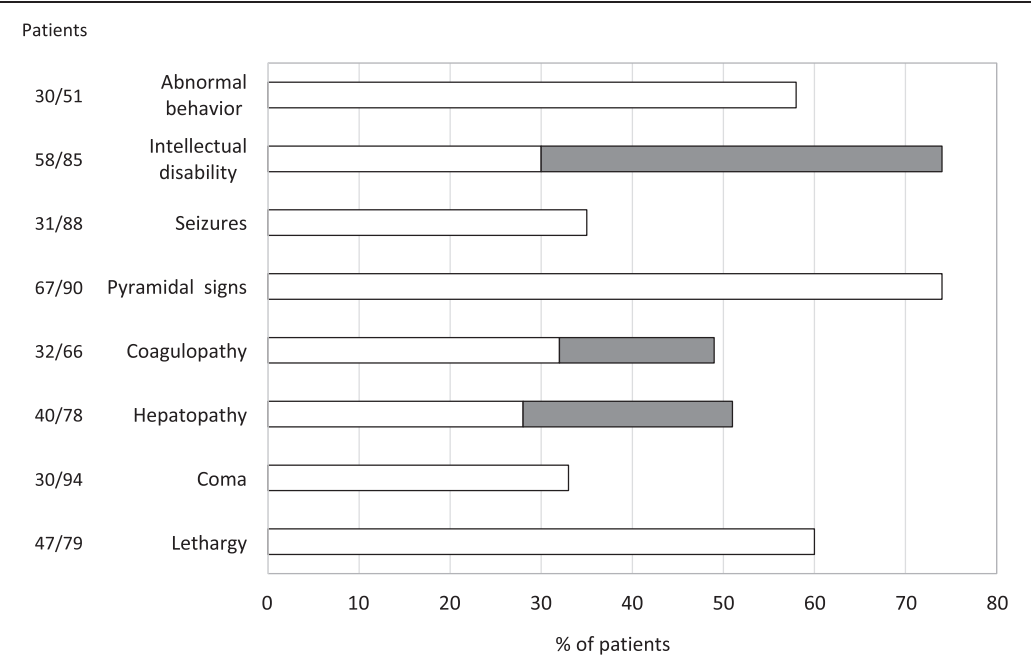

Figure 2 The graph shows the frequency of clinical features in HHH syndrome. For Intellectual disability we identified two categories: mild (IQ/DQ50-69)/modarate (IQ/DQ35-49) [white bars], and serve (IQ/DQ < 35) [gray barsj. A similar classification was adopted for hepatopathy [mild/moderate up to $10 \mathrm{x}$ ) or serve $(>10 \mathrm{x})$ increase of trans saminases] and coagulopathy [mild:nioderate individua coagulation factors $40 \%-70 \%$, INP 1.5-2.0) or serve (individual coagulation factors $<40 \%$, INP $>2.0$ or related clinical Manifestations) abnormalities of prothromibin time and INR).

presented with cognitive defect, being mild/moderate in $36 \%$ and severe in $38 \%$ of patients, respectively (Figure 2 ). A normal intellectual development was recorded in 29 out of 86 patients (34\%). However, some patients with normal cognitive development displayed behavioral problems [15,32]. The degree of ID doesn't seem to be proportionally related either to the frequency of lethargy/ coma episodes or to ammonium or ornithine concentrations in plasma, as suggested in literature [38]. Additional clinical features more rarely reported in some $\mathrm{HHH}$ syndrome patients include dysmorphic features, cerebral dysplasia $[5,6,46]$ and microcephaly $[14,57]$.

\section{Ocular findings}

Retinal involvement, with photophobia, hemeralopia, tapetoretinal degeneration, cataract and abnormal electroretinogram has also been reported $[37,38,44]$.

\section{Aetiology \\ Biochemical derangement and pathophysiology}

The biochemical role of ORC1 is complex and highly relevant for the different tissues where it is expressed. ORC1 transports ornithine, lysine and arginine into the mitochondrial matrix of peripheral tissues and pericentral hepatocytes; in periportal hepatocytes, in which UC enzymes are expressed, it catalyzes a very efficient ornithine/citrulline exchange reaction [65], connecting the enzyme activities of urea synthesis in the cytosol to those in the mitochondria. ORC1 plays therefore a key role in the UC (Figure 3). ORC1 catalyzes the transport of the L-isomers of ornithine, citrulline, lysine and arginine by a 1:1 substrate exchange reaction and less efficiently exchanges a basic amino acid for an $\mathrm{H}+$ [65-67].
Two human isoforms of the mitochondrial ornithine carrier, ORC1 and ORC2, have been identified so far. Despite having a high sequence identity (87\%) with ORC1, ORC2 is less active, presents a lower affinity for ornithine and citrulline, and shows a broader substrate specificity because of its capability to transport histidine and homocitrulline as well as the D-isomers of ornithine, lysine and arginine [68]. Both isoforms are mainly expressed in liver, pancreas, lungs, and testis, although ORC2 to a much lesser extent than ORC1 in all tissues investigated [68]. The total mitochondrial ornithine/ citrulline exchange activity per whole organ in vivo is unknown; it has been suggested that the late onset and the variable clinical phenotype of $\mathrm{HHH}$ syndrome may be due to the redundancy of this exchange activity $[8,37]$. This is catalyzed either by ORC2 [68] or by the SLC25A29 gene product (previously reported to be a mitochondrial carnitine/acylcarnitine- or ornithine-like carrier called ORNT3 [69]), which is able to rescue the ornithine metabolism deficiency in fibroblasts of $\mathrm{HHH}$ patients $[69,70]$ and to transport basic amino acids as well as ornithine into proteoliposomes [71]. The residual ornithine transport in cultured fibroblasts and liver of affected individuals supports this hypothesis of gene redundancy in $\mathrm{HHH}$ syndrome $[8,37]$.

ORC1 deficiency reduces the mitochondrial availability of ornithine, which increases in the cytosol causing hyperornithinemia. The accumulation of ornithine in cytosol leads also to increased levels of polyamines as spermine and spermidine [72]. In the periportal zone of the liver lobuli, the lower level of mitochondrial ornithine reduces the UC rate since the matrix ornithine is required by the ornithine transcarbamylase (OTC) to 


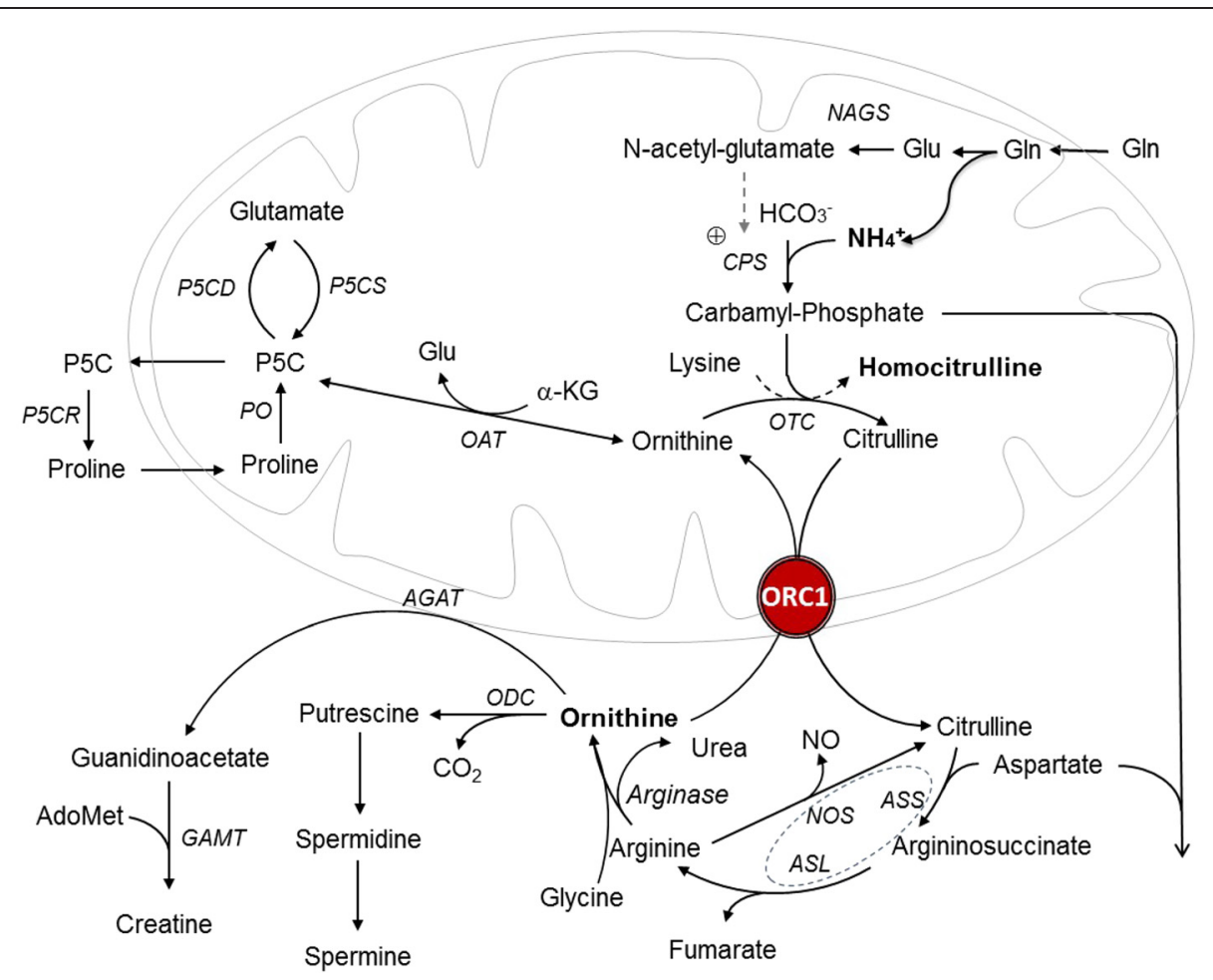

Figure 3 The urea cycle and related patwhays. The acronyms correspond to: NAGS, N-acetylglutamate synthase; CPS, carbamyl-phosphate synthetase; OTC omithine transcarbamylase; ORC1, ornithine carrier 1; ASS argininosuccinate synthetase; ASL argininosuccinate lyase; NOS, nitric oxide synthase: ODC ortnithine decarboxylase; AGAT, argine: glycine amidinotransferase; GAMT, guanidinoacetate N-methyltransferase; OAT, ornithine deltaaminotransferase; P5CD 1- pyrrolin-e5-carboxylate dehydrogenase; P5CS, 1-pyrroline-5 carboxylate synthetase; P5CR, 1-pyrroline-5-carboxylate reductase; PO, proline oxidase. The dashed circle indicates the multiprotien complex, which also includes cationic aminoacid transporter 1 (CAT1) and heat shock protein 90 (HSP 90).

prime the UC. Ammonia and carbamyl-phosphate (CP) levels increase, explaining hyperammonemia. Increased $\mathrm{CP}$ may have two destinations: it may bind lysine, forming homocitrulline which gives rise to homocitrullinuria or enter in the pyrimidine pathway, leading to increased excretion of orotic acid in urine (Figure 3). Plasma glutamine is taken up from the systemic circulation into the gut and then processed to glutamate, pyrroline-5carboxylate, ornithine and citrulline. As the liver extracts only a small quantity of citrulline, this aminoacid is mainly transported to the kidney and metabolized to arginine in the tubules of the cortical zone and used for guanidino acetate synthesis by arginine-glycine amidotransferase (AGAT), the first step of creatine synthesis, with ornithine as by-product [73]. In ORC1 deficiency, the high cytosolic ornithine concentrations inhibit AGAT leading to secondary creatine deficiency $[21,44,74]$. Secondary creatine deficiency may be also due to low cellular arginine availability due to the block in UC flow. Moreover, ornithine excess may inhibit creatine biosynthesis as observed in ornithine delta-aminotransferase (OAT) deficiency [75,76] (Figure 3). This is in line with a previous observation of two patients with $\mathrm{HHH}$ syndrome, in whom urinary creatine excretion was normalized by citrulline and arginine but not by ornithine supplementation [21].

Since ORC1 is highly expressed in the brain and in particular in astrocytes, one could speculate that an 7absent or dysfunctional protein may affects the metabolism of neurons and of glial cells. Hyperammonemia has a toxic effect on the astrocytes, causing mitochondrial dysfunction, cellular swelling and a change in cellular bioenergetics [77]. Moreover, Braissant et al. [78] have shown through in vitro experiments with reaggregated mixed brain cells (neurons, astrocytes, oligodendrocytes and microglia) primary cultures, impaired axonal growth and abnormal localization and phosphorylation of the intermediate neurofilament M-protein after ammonia exposure. Addition of creatine to the media seems to protect against this effect of ammonia on the neural cytoskeleton; this protective effect depends on the presence of glial cells and cannot be observed in neuron enriched cell cultures (78). These findings suggest that in ORC1 deficiency AGAT inhibition due to high ornithine levels reduces the endogenous creatine production in cerebrum and cerebellum and thus renders the brain more vulnerable to a local increase of ammonia [78]. 
Recently, Viegas et al. have shown that excessive ornithine and homocitrulline levels can cause protein and lipid oxidation and may negatively interfere in oxidative phosphorylation and Krebs cycle function of the rat brain, with secondary oxidative stress $[79,80]$. Impairment of brain bioenergetics and the oxidative damage induced by these metabolites may possibly contribute to the neurological symptoms affecting patients with $\mathrm{HHH}$ syndrome.

\section{Molecular genetics}

$\mathrm{HHH}$ syndrome is a genetic autosomal recessive disease caused by mutations in the SLC25A15 (solute carrier family 25, member 15) gene [37]. This gene maps on chromosome 13q14.11, spans about $23 \mathrm{~kb}$ and contains 7 exons encoding for the isoform 1 of the ornithine carrier ORC1, a member of the mitochondrial carrier family [65]. The open reading frame is encoded by exons 2 through 7 [53]. Exon 1 encodes part of the 5'UTR. The normal product of SLC25A15 gene is a 301 amino acid protein composed, like other mitochondrial carriers, of six $\alpha$-helices that traverse the inner mitochondrial membrane with the $\mathrm{C}$ - and N-termini exposed to the cytosolic side of the membrane. ORC1 shows a tripartite structure with three similar domains each with two transmembrane helices connected by a long hydrophilic matrix loop [65]. There is experimental evidence for the direct involvement of the ORC1 residues E77, R179 and E180 in substrate binding, whereas W224 and R275 seem to be important in triggering the substrate-induced conformational changes that leads to substrate translocation; N74 and N78 residues are part of the substrate binding pocket [81] (Figure 4).

Several SLC25A15 mutations have been associated with the clinical phenotype of the $\mathrm{HHH}$ syndrome. From
1999 to 2014, 35 mutations have been identified: 18 missense mutations, 7 small insertion, 2 small deletions, 4 nonsense mutations, 1 gross deletion, 1 micro-rearrangement, 1 intronic rearrangement (Table 1). All mutations occurred in the coding region. Two common mutations, p.F188del and p.R179*, are reported. The first accounts for about 30\% of patients with the $\mathrm{HHH}$ syndrome and it is characteristic (but not exclusive) of patients of French-Canadian descent because of a founder effect [38]. The second mutation (15\% of $\mathrm{HHH}$ patients) appears to be prevalent in patients of Japanese and Middle Eastern origin [27,47,57].

The functional effects of some SLC25A15 mutations on substrate transport have been investigated using in vitro cell culture and liposome reconstitution studies $[53,57,68]$, revealing that some SLC25A15 missense and nonsense mutations (p.T32R, p.F188del, p.G190D, p.M273K, p.T272I, p.G113C, p.L71Q and p.L283F) cause reduced transport activity while others (p.G220R, p.R179*, p.G27R, p.R275Q and $\mathrm{R} 275^{*}$ ) completely abolish the function. Interestingly, some patients with null SLC25A15 alleles did not show neonatal hyperammonemia [57].

The 18 pathogenic missense mutations alter residues phylogenetically conserved in the wild-type protein, which may reflect that they have specific important roles for function. However, the majority of the single-residue mutations causing the $\mathrm{HHH}$ syndrome are non-conservative substitutions that in many cases introduce a change in the charge of amino acid side chain (p.A15E, p.G27R, p.G27E, p.T32R, p.M37R, p.P126R, p.E180K, p.G190D, p.G220R, p.M273K, p.R275G and p.R275Q) [22,37,57], prolines (p.L193P and p.A264P) or residues with different side chain size or polarity (p.A15V, p.G113C, p.G216S, p.T272I, p.L71Q, p.F188L and p.L283F) [57,60], that alter the protein structure and function. Missense mutations can be

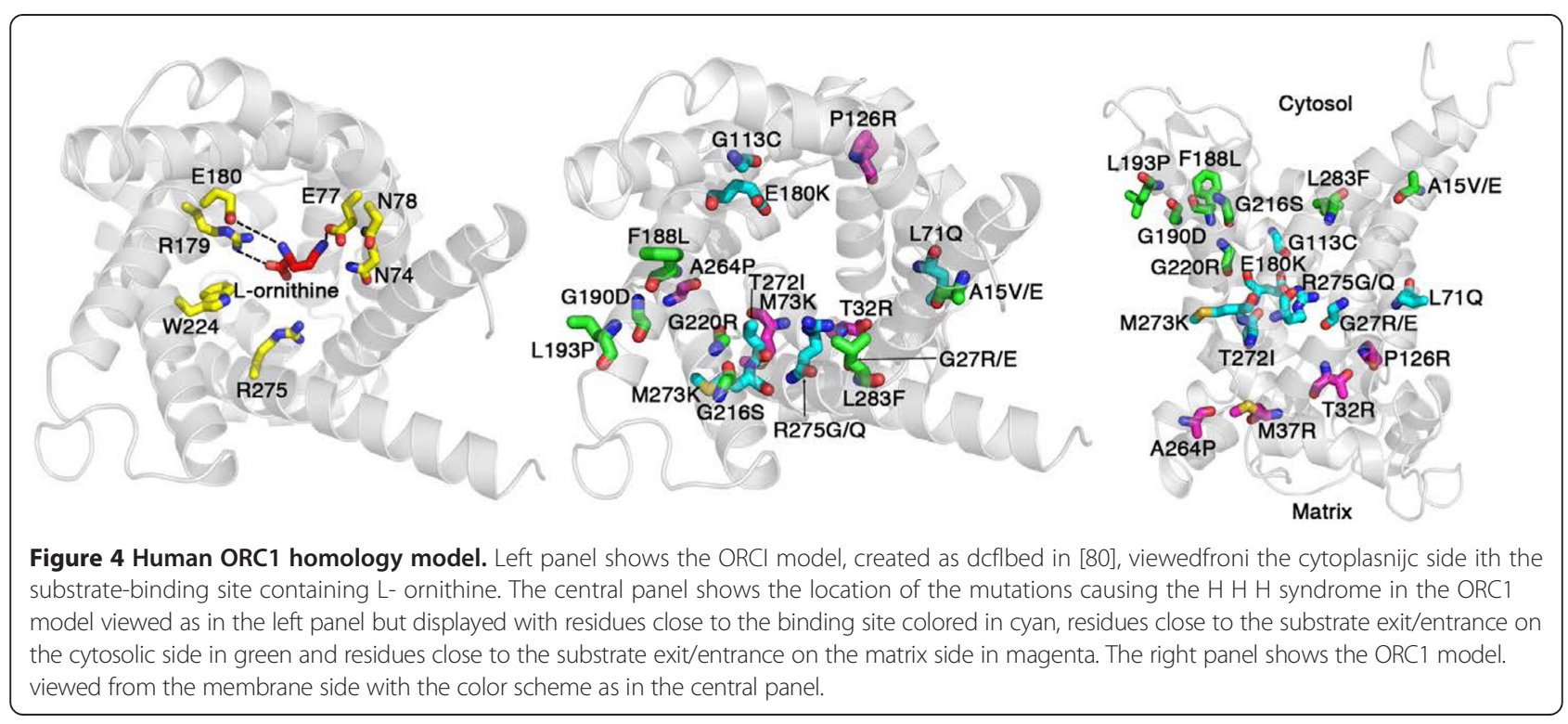


mapped onto the 3D structural homology model of ORC1 [81], which is based on the structure of the carboxyatractyloside inhibited bovine ADP/ATP carrier (PDB ID 1OKC), to display the location of each mutation (Figure 4). In a simple analysis, the mutations may be divided into three groups depending on their location in the model: residues close to the proposed binding site, residues close to the substrate entrance/exit on the cytosolic side and residues close to the substrate exit/entrance on the matrix side. The majority of the $\mathrm{HHH}$ syndrome mutations are found in residues that have side chains protruding into the internal pore of ORC1 where the substrate is translocated, suggesting that these mutations could interfere with substrate translocation. Mutations located in residues of the substrate binding site p.E180K, p.R275G and p.R275Q are presumably directly deleterious to substrate binding and other mutations in proximity, such as p.G27R, p.G27E, p.T272I and p.G113C, probably have an effect in deforming the substrate-binding pocket. Mutations on the cytosolic side, such as p.F188L, p.G190D, p.G216S and p.G220R, could interfere with the substrate entering or exiting its binding site, or with the closing/opening of the substrate-binding cavity towards the cytosol. A similar explanation could be given for the effect of p.T32R and p.A264P mutations that interfere with the closing/opening of the substrate-binding cavity but on the matrix side. The residues A15, M37, L71, P126, L193 and M273 have side chains on the external surface of ORC1 and therefore these mutations cannot directly obstruct substrate translocation. Instead these mutations may indirectly impair function, probably by causing local perturbations in the ORC1 structure, e.g., the proline of the p.P126R mutation is located in one of the signature motifs that are highly conserved in all mitochondrial carriers and is likely to be crucial for the structure and conformational changes during substrate translocation [72]

\section{Diagnosis}

\section{Biochemical profile}

The metabolic triad of hyperammonemia, hyperornithinemia, and urinary excretion of homocitrulline establishes the diagnosis of HHH syndrome. However, some patients may present with an incomplete biochemical phenotype. The biochemical data in individuals with $\mathrm{HHH}$ syndrome at the time of diagnosis are summarized in Table 2 and in Additional file 1: Table S1. Of note, $\mathrm{HHH}$ syndrome is characterized by a lower degree of hyperammonemia if compared with other UCDs [1] and plasma ammonia level usually normalizes in response to pharmacological treatment.

Plasma concentration of ornithine can range from 216 to $1915 \mu \mathrm{mol} / \mathrm{L}$ (normal: 30-110 $\mu \mathrm{mol} / \mathrm{L}$ ). Despite proteinrestricted diet in combination with pharmacological treatment, ornithine concentration in plasma remains elevated with only a very few patients reported with normal levels at long-term follow-up [2-4,15,48,56].
Table 2 Biochemical data (mean \pm SD, range, and number of patients) detected in plasma of $\mathrm{HHH}$ syndrome patients at diagnosis

\begin{tabular}{lll}
\hline Metabolites & HHH patients & Reference value \\
\hline Ammonia & $215 \pm 279(18-2300) n=93$ & $<55$ \\
Ornithine & $575 \pm 265(216-1915) n=96$ & $30-110$ \\
Citrulline & $26 \pm 14(1-57) n=21$ & $10-52$ \\
Glutamine & $1149 \pm 592(447-3688) n=43$ & $333-809$ \\
Arginine & $66 \pm 26(27-126) n=22$ & $20-112$ \\
Lysine & $178 \pm 177(35-858) n=26$ & $80-257$ \\
\hline
\end{tabular}

Values are expressed as $\mu \mathrm{mol} / \mathrm{L}$

Homocitrullinuria is a hallmark of the disease, however some patients may show absent or only minimal excretion of homocitrulline in urine [50] (Additional file 1: Table S1).

Similarly to other UCDs [1], plasma glutamine concentrations and urinary orotic acid may be elevated (Additional file 1: Table S1). Occasional organic aciduria, with increase excretion of Krebs Cycle intermediates (succinate, citrate, fumaric, $\alpha$-ketoglutaric) and lactate was reported $[50,52]$.

\section{Study of intracellular mitochondrial transport of radiolabelled ${ }^{14} \mathrm{C}$-ornithine in cultured skin fibroblasts}

The diagnosis of HHH syndrome may be confirmed by the evaluation of cellular mitochondrial transport of radiolabelled ${ }^{14} \mathrm{C}$-ornithine in cultured skin fibroblasts [9]. Cultured fibroblasts from patients with null mutations usually show an approximately $75 \%-80 \%$ reduction in ornithine transport: this may suggest a potential role of redundant transporters in achieving a residual transport $[37,69]$. There is no correlation between ornithine transport capacity, genotype and phenotype $[37,53]$.

\section{Other investigations}

As detected by computer tomography (CT) scan and magnetic resonance (MRI) studies, brain abnormalities include mild cerebral and cerebellar atrophy [16,23,31, $27,57]$, white matter changes $[4,57,59]$, subdural hematoma [C. Dionisi-Vici, personal observation], cystic lesions and calcifications [4], and diffuse brain edema, evident at ultrasound scan [35]. However, normal brain CT scan or MRI findings were reported in several patients, mainly in those who did not experience an overt hyperammonemic coma $[36,40,60]$. Interestingly, multiple stroke-like lesions were reported in a 4 year-old patient presenting irritability, vomiting, highly elevated liver enzymes, hyperammonemia, and coagulopathy [56].

Neurophysiologic studies show abnormal motor evoked potentials affecting pyramidal tract of lower limbs, generally without upper limb involvement [24,36]. Somatosensory evoked potentials are normal; electroneuromyography can 
show abnormal nerve conduction velocity [24,36,37,51] and may reveal signs of spinal anterior horn cells degeneration [34].

Blood coagulation studies may be abnormal with deficiency of factor VII, X, XI, and antithrombin III [7,15,21,38,39,55-57].

Liver structural (light microscopy) and ultrastructural changes (electron microscopy) are commonly observed $[7,9,26,40,57,82]$ and include vacuolated hepatocytes with intracytoplasmic glycogen deposition, small nuclei, dense chromatin, and fat droplets without fibrosis. At electron microscopy, mitochondria appear abnormally shaped and sized with lamellar cristal-like inclusions [11].

\section{Differential diagnosis Hyperammonemia}

$\mathrm{HHH}$ syndrome enters in the differential diagnosis of any patient presenting with hyperammonemia at any age. The main causes of hyperammonemia associated with inborn errors of metabolism include $[1,83]$ : UCDs (they generally present along with elevation in plasma ammonia concentration, hyperglutaminemia and metabolic alkalosis); organic acidemias (they show in addition metabolic acidosis, ketonuria and normal or reduced plasma glutamine levels); fatty-acid oxidation defects (hyperammonemia is associated with hypoglycaemia, hypertransaminasemia, increase of plasma creatine-phosphokinase levels); lysinuric protein intolerance (characterized by low concentrations of plasma ornithine, lysine, and arginine and persistent urinary excretion of lysine, ornithine, and arginine); hyperinsulinism-hyperammonemia syndrome (characterized by severe hypoglycaemia); pyruvate carboxylase deficiency (presenting with lactic acidosis and hypoglycaemia); and the recently reported defect of mitochondrial carbonic anhydrase VA (presenting with lactic acidosis, hypoglycaemia and a characteristic organic aciduria) [84].

A complete routine chemistry panel [i.e. blood ammonia, glucose, lactate, liver function tests (including transaminases, gamma-GT, coagulation, bilirubin, albumin) creatine kinase, uric acid, arterial blood gases, and blood cell counts, urinalysis], and metabolic investigations with plasma amino acids, urine amino acids,organic acids and orotic acid measurements allow the differential diagnosis.

\section{Hyperornithinemia}

Hyperornithinemia is also a characteristic feature of OAT deficiency responsible for gyrate atrophy of the choroid and retina (OMIM \#258870) [85]. This disorder is caused by defect in $O A T$ gene, located at $10 \mathrm{q} 26$. The fasting plasma ornithine in OAT deficiency ranges from 400 to $1400 \mu \mathrm{mol} / \mathrm{L}$ [85]. Initial symptoms include myopia and night blindness, starting in early to mid-childhood; patients then develop reduction of visual fields, posterior subcapsular cataracts and abnormal electroretinogram
[85]. The fundoscopic aspect of the chorioretinal atrophy in gyrate atrophy is highly specific. Patients have generally a normal cognitive level, although one large series suggests an increased incidence of intellectual impairment [76]. A few OAT patients experienced neonatal hyperammonemia [86]. Interestingly, and similarly to some $\mathrm{HHH}$ patients, they were all found to have normal plasma ornithine concentration at birth which progressively increased in the following weeks when the diagnosis was fully defined [86].

\section{Homocitrullinuria}

Other conditions in which homocitrullinuria can be observed should be listed in the differential diagnosis of $\mathrm{HHH}$ syndrome. These include lysinuric protein intolerance (MIM\# 222700) or OTC deficiency (MIM\# 311250), which can present in some cases with low quantity of homocitrulline in urine $[87,88]$. Furthermore, canned food or heated milk products may represent a source of detectable homocitrulline in urine [88].

\section{Neurologic findings}

In patients with early childhood onset of gait abnormalities and spasticity, the differential diagnosis includes cerebral palsies and inherited spastic paraplegias. Interestingly among the inherited disorders of the UC, $\mathrm{HHH}$ syndrome and argininemia share the peculiar neurological feature of pyramidal dysfunction $[1,88,89]$.

\section{Newborn screening}

In some countries, like United States and Canada, HHH syndrome is included in the disease panel of expanded newborn screening programs. However, it may be missed on newborn screening because some affected neonates may not show in the first days of life elevated plasma ornithine levels that can be detected by tandem mass spectroscopy [90]. Authors suggested that the typical rise of plasma ornithine levels occurs after the first few days of life when blood samples for newborn screening are obtained.

\section{Genetic diagnosis}

Genetic testing is the gold standard to confirm the diagnosis. The SLC25A15 gene was cloned in 1999 and a common F188del mutation in French Canadian patients was identified [37]. Genetic analysis does not have a prognostic value since even in the same family and with the same mutation the phenotype can be quite variable. Sequence analysis is performed first, followed by deletion/duplication analysis if only one or no mutant SLC25A15 alleles are detected. The gold standard for prenatal diagnosis in couples of known genotype is mutation analysis. Before the discovery of the molecular basis of $\mathrm{HHH}$ syndrome, prenatal diagnosis has been 
performed by the analysis of ornithine incorporation in cultured amniotic fluid cells $[35,41]$.

\section{Management}

Acute treatment is similar to other UCDs [1]. Protein intake must be stopped for $24 \mathrm{~h}$ and intravenous glucose in combination with first-line medications must be started. Arginine (and/or citrulline) must be administered to replace the missing UC intermediates and to allow protein synthesis. Ammonia scavengers as sodium benzoate and sodium phenylbutyrateare used for bypassing the UC block. Long-term treatment is based on a low-protein diet supplemented with citrulline or arginine; ornithine supplementation has been tried in the past with contradictory results $[4,18,21,24,25,31]$ in the attempt to correct ornithine depletion in the mitochondria, however its use is not recommended. Protein restriction may be combined with sodium benzoate or sodium phenylbutyrate. If plasma creatine levels are low, creatine supplementation should be instituted $[1,44,74]$. Citrulline supplementation has been shown to allow better metabolic control and to avoid secondary creatine deficiency [21]. The retrospective review of the literature provided information on treatment modalities in $\mathrm{HHH}$ patients. All were treated with low protein diet, $22 \%$ with protein restriction alone. Thirty per cent of patients received arginine supplementation, $22 \%$ citrulline and $10 \%$ ornithine; $36 \%$ were treated with ammonia scavengers, (21\% benzoate, $12 \%$ phenylbutyrate, and $3 \%$ combined benzoate and phenylbutyrate). To our knowledge, liver transplantation was done only in one $\mathrm{HHH}$ patient with severe metabolic derangement [54]. The main parameters to be monitored at follow-up are similar to other UCDs [1], and include plasma ammonia, plasma aminoacids and urinary orotic acid.

\section{Prognosis}

Prognosis is highly variable ranging from mild neurological involvement to a severely disabling disease (Table 1). Out of the 106 patients with a known vital status (median age 14 years, range 1 month -57 years), 7 patients died, representing an overall mortality rate of the $6,6 \%$. An appropriate management with protein restriction diet, supplements and ammonia scavengers allows almost normal life duration. Treated patients are usually metabolically stable and do not experience relapses of hyperammonemia [38]. Hepatic signs resolve rapidly with treatment and long-term hepatic function is normal [52]. Chronic therapy prevents hyperammonemia and liver disease but does not affect the spastic paraparesis [21,22,38]. Successful pregnancies have been reported in $\mathrm{HHH}$ syndrome female patients $[4,7,29]$.

\section{Unresolved questions}

Although the disease responds well to treatment with low risk of relapse of hyperammonemia [38], slowly progressive pyramidal signs characterize the chronic course, as also seen in argininemia [89]. However, the mechanism(s) of pyramidal dysfunction in $\mathrm{HHH}$ syndrome still remains to be elucidated. Creatine deficiency may contribute to the pathogenetic mechanism of the syndrome, as creatine is relevant for mitochondrial energy metabolism, regulation of glycolysis, proteins synthesis, membrane stabilization and neuromodulation $[77,78,85]$. This could be in line with the finding of abnormally shaped mitochondria at electron microscopy studies in skin fibroblasts, hepatocytes and muscle biopsy from $\mathrm{HHH}$ syndrome patients $[11,23,82]$. Furthermore, a mitochondrial dysfunction has been recently related to the effects of ornithine and homocitrulline in causing oxidative stress and disturbed mitochondrial homeostasis $[79,80]$.

A further mechanism that can be involved in the pathophysiology of $\mathrm{HHH}$ syndrome is related to polyamines metabolism. Shimizu and colleagues reported increased total and fractional (putrescine, cadaverine, spermine, spermidine) polyamines in one $\mathrm{HHH}$ syndrome patient [30]. Indeed, the clinical similarities between HHH syndrome and argininemia, which has been associated to an abnormal polyamine metabolism [91,92], may suggest a common pathogenetic mechanism causing pyramidal dysfunction.

Overall, the pathogenesis of $\mathrm{HHH}$ syndrome is complex and not completely understood. It is likely that different mechanisms, including the impact of low mitochondrial ornithine on UC flux, the presence of hyperammonemic crises and the disturbance of other pathways in major organs play a role in determining the heterogeneous clinical presentation of ORC1 deficiency.

In addition, as molecular studies failed to disclose a correlation between type of mutations or ornithine transport capacity and disease severity, an effect of genetic modifiers, such as ORC genes redundancy, seems to be likely, but further studies are certainly needed to clarify this point.

Interestingly, there is a report describing hyperammonemic encephalopathy in two consanguineous weanling foals presenting postweaning with anorexia, abnormal behaviour, unthriftiness, and poor growth [93]. Hyperammonemia was associated with increased transaminases, abnormal coagulation, and mild hyperbilirubinemia. The animal presented with severe neurologic abnormalities, including circling, bilateral forelimb and hindlimb ataxia, and dementia. Biochemical investigations revealed an aminoacid profile consistent with $\mathrm{HHH}$ syndrome with elevated serum ornithine and glutamine, homocitrullinuria and orotic aciduria, highlighting the strong similarities between the human disease and this spontaneous animal model. 


\section{Conclusions}

In this article, we have retrospectively reviewed the clinical and metabolic profiles of all reported $\mathrm{HHH}$ syndrome patients. The combination of peculiar clinical features and the biochemical triad of hyperammonemia, persistent hyperornithinemia, and urinary excretion of homocitrulline, allows the diagnosis of $\mathrm{HHH}$ syndrome. Encephalopathy, coagulopathy and liver disease are common acute features, whereas pyramidal dysfunction and cognitive disabilities typically characterize the chronic course of the disease. The clinical phenotype is extremely variable and its severity does not correlate with the genotype or with recorded ammonium/ ornhitine plasma levels. The pathophysiological mechanisms underlying $\mathrm{HHH}$ syndrome have not been fully elucidated yet, but they seem to include features common to both primary UCDs as well as to mitochondrial disorders.

\section{Additional file}

Additional file 1: Table S1. The table summarizes the relevant laboratory findings at diagnosis in 111 patients with $\mathrm{HHH}$ syndrome. Values of ammonia and glutamine are expressed as $\mu \mathrm{mol} / \mathrm{L}$. Urinary orotate and homocitrulline (when possible) are expressed as $\mu \mathrm{mol} / \mathrm{mmol}$ creatinine.

\section{Abbreviations}

AGAT: Arginine-glycine amidotransferase; CP: Carbamyl-phosphate; $\mathrm{HHH}$ : Hyperornithinemia- hyperammonemia-homocitrullinuria; ID: Intellectual disability; OAT: Ornithine delta-aminotransferase; ORC1: Ornithine carrier 1; OTC: Ornithine transcarbamylase; UC: Urea cycle; UCDs: Urea cycle disorders.

\section{Competing interests}

The authors declare that they have no competing interests.

\section{Authors' contributions}

All authors were involved in the preparation of the draft manuscript and have read, critically reviewed and approved the final version of the manuscript for publication.

\section{Acknowledgements}

This work was supported with founds "Ricerca Corrente" by the Italian Ministry of Health. We thank the Association "La Vita e' un Dono" for supporting the fellowship of Dr. Diego Martinelli. Preliminary results of this study were presented at The Milupa International Workshop on $\mathrm{HHH}$ Syndrome held in Rome, Italy, 24 March 2006. A special thanks to Claude Bachmann who introduced CD-V to this subject.

\section{Author details}

'Division of Metabolism, Children Research Hospital Bambino Gesù, Rome, Italy. ${ }^{2}$ Neuromuscular and Neurodegenerative Diseases Unit, Children Research Hospital Bambino Gesù, Rome, Italy. ${ }^{3}$ Medical Genetics Division, Catholic University Policlinico Gemelli, Rome, Italy. ${ }^{4}$ Sciences Department, Università della Basilicata, Potenza, Italy. ${ }^{5}$ Biosciences, Biotechnologies and Biopharmaceuticals Department, Biochemistry e Molecular Biology Lab, Università di Bari, Bari, Italy

Received: 5 November 2014 Accepted: 13 February 2015

Published online: 11 March 2015

\section{References}

1. Häberle J, Boddaert N, Burlina A, Chakrapani A, Dixon M, Huemer M, et al. Suggested guidelines for the diagnosis and management of urea cycle disorders. Orphanet J Rare Dis. 2012;7:32.

2. Shih VE, Efron ML, Moser HW. Hyperornithinemia, Hyperammonemia and Homocitrullinuria. Am J Dis Child. 1969;117:83-92.
3. Shih VE, Mandel R. Metabolic defect in hyperornithinaemia. Lancet. 1974;2:1522-3.

4. Kim SZ, Song WJ, Nyhan WL, Ficicioglu C, Mandell R, Shih VE. Long-term follow-up of four patients affected by $\mathrm{HHH}$ syndrome. Clin Chim Acta. 2012:413:1151-5.

5. Wright T, Pollitt R. Psychomotor retardation, epileptic and stuporous attacks, irritability and ataxia associated with ammonia intoxication, high blood ornithine levels and increased homocitruline in the urine. Proc R Soc Med. 1973;66:221.

6. Fell V, Pollitt RJ, Sampson GA, Wright T. Ornithinemia, hyperammonemia, and homocitrullinuria: a disease associated with mental retardation and possibly caused by defective mitochondrial transport. Am J Dis Child. 1974;127:752-6.

7. Gatfield PD, Taller E, Wolfe DM, Haust MD. Hyperornithinemia, hyperammonemia, and homocitrullinuria associated with decreased carbamyl phosphate synthetase I activity. Pediatr Res. 1975;9:488-97.

8. Haust MD, Gatfield PD, Gordon BA. Ultrastructure of hepatic mitochondria in a child with hyperornithinemia, hyperammonemia, and homocitrullinuria. Hum Pathol. 1981;12:212-22.

9. Hommes FA, Ho CK, Roesel RA, Coryell ME, Gordon BA. Decreased transport of ornithine across the inner mitochondrial membrane as a cause of hyperornithinaemia. J Inherit Metab Dis. 1982;5:41-7.

10. Gordon BA, Gatfield DP, Haust MD. The hyperornithinemia, hyperammonemia, homocitrullinuria syndrome: an ornithine transport defect remediable with ornithine supplements. Clin Invest Med. 1987;10:329-36.

11. Haust MD, Dewar RA, Gatfield DP, Gordon BA. Hyperornithinemiahyperammonemia-homocitrullinuria $(\mathrm{HHH})$-syndrome. Ultrastructural changes of mitochondria in cultured dermal fibroblasts of three patients. Pathol Res Pract. 1996:192:271-80.

12. Haust MD. Ciliated cultured dermal fibroblasts in a patient withhyperornithinemia, hyperammonemia and homocitrullinuria $(\mathrm{HHH})$ syndrome. Pathol Res Pract. 1995;191:1062-5.

13. Winter HS, Perez-Atayde AR, Levy Shih VE. Unique hepatic ultrastructura change in a patient with hyperammonemia (HAM), Hyperornithinaemia (HOR) and homocitrullinuria (HC). Pediatr Res. 1980;14:583.

14. Sabetta G, Lombardi A, Castro M, Scappaticci A, Giampaolo R. Iperammoniemia, iperornitinemia, omocitrullinuria: descrizione di un caso. Aggiorn Pediatr. 1980;XXXI:9-10.

15. Zamboni G, Marradi P, Praderio R, Dall'Agnola A. Hyperammonemia with hyperornithinaemia and homocitrullinuria in two brothers. Acta Med Auxol. 1982;14:121-6.

16. Oyanagi K, Tsuchiyama A, Itakura Y, Sogawa H, Wagatsuma K, Nakao T, et al. The mechanism of hyperammonaemia and hyperornithinaemia in the syndrome of hyperornithinaemia, hyperammonaemia with homocitrullinuria. J Inherit Metab Dis. 1983;6:133-4

17. Hommes FA, Roesel RA, Metoki K, Hartlage PL, Dyken PR. Studies on a case of $\mathrm{HHH}$-syndrome (hyperammonemia, hyperornithinemia, homocitrullinuria) Neuropediatrics. 1986;17:48-52.

18. Kirsch SE, McInnes RR. Control of hyperammonemia in the $3 \mathrm{H}$ syndrome by ornithine administration. Pediatr Res. 1986;20:267A

19. Gjessing LR, Lunde HA, Undrum T, Broch H, Alme A, Lie SO. A new patient with hyperornithinaemia, hyperammonaemia and homocitrullinuria treated early with low protein diet. J Inherit Metab Dis. 1986;9:186-92.

20. Haass C, Pedicino R, Sabetta G, Panero A, Colarizi P. Hyperornithinaemia, hyperammonemia and homocitrullinuria (H.H.H. syndrome) with neonatal onset and favourable outcome. Ital J Pediatr. 1986:12:143-6.

21. Dionisi Vici C, Bachmann C, Gambarara M, Colombo JP, Sabetta G. Hyperornithinemia-hyperammonemia-homocitrullinuria syndrome: low creatine excretion and effect of citrulline, arginine, or ornithine supplement. Pediatr Res. 1987;22:364-7.

22. Salvi S, Dionisi-Vici C, Bertini E, Verardo M, Santorelli FM. Seven novel mutations in the ORNT1 gene (SLC25A15) in patients with hyperornithinemia, hyperammonemia, and homocitrullinuria syndrome. Hum Mutat. 2001:18:460.

23. Salvi S, Santorelli FM, Bertini E, Boldrini R, Meli C, Donati A, et al. Clinical and molecular findings in hyperornithinemia-hyperammonemia-homocitrullinuria syndrome. Neurology. 2001;57:911-4

24. Koike R, Fujimori K, Yuasa T, Miyatake T, Inoue I, Saheki T. Hyperornithinemia, hyperammonemia, and homocitrullinuria: case report and biochemical study. Neurology. 1987;37:1813-5

25. Rodes M, Ribes A, Pineda M, Alvarez L, Fabregas I, Fernandez Alvarez E, et al. A new family affected by the syndrome of hyperornithinaemia, hyperammonaemia and homocitrullinuria. J Inherit Metab Dis. 1987;10:73-81. 
26. Nakajima M, Ishii S, Mito T, Takeshita K, Takashima S, Takakura H, et al. Clinical, biochemical and ultrastructural study on the pathogenesis of hyperornithinemia-hyperammonemia-homocitrullinuria syndrome. Brain Dev. 1988;10:181-5.

27. Miyamoto T, Kanazawa N, Kato S, Kawakami M, Inoue Y, Kuhara T, et al. Diagnosis of Japanese patients with $\mathrm{HHH}$ syndrome by molecular genetic analysis: a common mutation, R179X. J Hum Genet. 2001;46:260-2.

28. Inoue I, Saheki T, Kayanuma K, Uono M, Nakajima M, Takeshita K, et al. Biochemical analysis of decreased ornithine transport activity in the liver mitochondria from patients with hyperornithinemia, hyperammonemia and homocitrullinuria. Biochim Biophys Acta. 1988;964:90-5.

29. Wong P, Lessick M, Kang S, Nelson M. Maternal hyperornitinaemiahyperammonemia-homocitrullinuria $(\mathrm{HHH})$ syndrome. Hum Genet. 1989:45(suppl):A14.

30. Shimizu H, Maekawa K, Eto Y. Abnormal urinary excretion of polyamines in $\mathrm{HHH}$ syndrome (hyperornithinemia associated with hyperammonemia and homocitrullinuria). Brain Dev. 1990;12:533-5.

31. Tsujino S, Kanazawa N, Ohashi T, Eto Y, Saito T, Kira J, et al. Three novel mutations (G27E, insAAC, R179X) in the ORNT1 gene of Japanese patients with hyperornithinemia, hyperammonemia, and homocitrullinuria syndrome. Ann Neurol. 2000;47:625-31.

32. Tuchman M, Knopman DS, Shih VE. Episodic hyperammonemia in adult siblings with hyperornithinemia, hyperammonemia, and homocitrullinuria syndrome. Arch Neurol. 1990;47:1134-7.

33. Tsujino S, Suzuki T, Azuma T, Higa S, Sakoda S, Kishimoto S. Hyperornithinemia, hyperammonemia and homocitrullinuria-a case report and study of ornithine metabolism using in vivo deuterium labelling. Clin Chim Acta. 1991;201:129-33.

34. Shigeto H, Yamada T, Kobayashi T, Goto I. A case of hyperornithinemiahyperammonemia-homocitrullinuria $(\mathrm{HHH})$ syndrome with spastic paraparesis and severe distal muscle atrophy of lower limbs. Rinsho Shinkeigaku. 1992;32:729-32.

35. Shih VE, Laframboise R, Mandell R, Pichette J. Neonatal form of thehyperornithinaemia, hyperammonaemia, and homocitrullinuria $(\mathrm{HHH})$ syndrome and prenatal diagnosis. Prenat Diagn. 1992;12:717-23.

36. Lemay JF, Lambert MA, Mitchell GA, Vanasse M, Valle D, Arbour JF, et al. Hyperammonemia-hyperornithinemia-homocitrullinuria syndrome: neurologic, ophthalmologic, and neuropsychologic examination of six patients. J Pediatr. 1992;121:725-30

37. Camacho JA, Obie C, Biery B, Goodman BK, Hu CA, Almashanu S, et al. Hyperornithinaemia-hyperammonaemia-homocitrullinuria syndrome is caused by mutations in a gene encoding a mitochondrial ornithine transporter. Nat Genet. 1999;22:151-8.

38. Debray FG, Lambert M, Lemieux B, Soucy JF, Drouin R, Fenyves D, et al. Phenotypic variability among patients with hyperornithinaemiahyperammonaemia-homocitrullinuria syndrome homozygous for the delF188 mutation in SLC25A15. J Med Genet. 2008:45:759-64.

39. Simell O, Mackenzie S, Clow CL, Scriver CR. Ornithine loading did not prevent induced hyperammonemia in a patient with hyperornithinemiahyperammonemia-homocitrullinuria syndrome. Pediatr Res. 1985;19:1283-7.

40. Smith L, Lambert MA, Brochu P, Jasmin G, Qureshi IA, Seidman EG Hyperornithinemia, hyperammonemia, homocitrullinuria $(\mathrm{HHH})$ syndrome: presentation as acute liver disease with coagulopathy. J Pediatr Gastroenterol Nutr. 1992;15:431-6.

41. Gray RG, Green A, Hall S, McKeown C. Prenatal exclusion of the $\mathrm{HHH}$ syndrome. Prenat Diagn. 1995;15:474-6.

42. Zammarchi E, Ciani F, Pasquini E, Buonocore G, Shih VE, Donati MA. Neonatal onset of hyperornithinemia-hyperammonemia-homocitrullinuria syndrome with favorable outcome. J Pediatr. 1997;131:440-3.

43. Shih VE, Ficicioglu C. Genotype and phenotype finding in hyperornithinaemia-hyperammonemia-homocitrullinuria $(\mathrm{HHH})$ syndrome. J Inherit Metab Dis. 2000;23(Suppl):72.

44. Morini C, Capozzi P, Boenzi S, Rizzo C, Santorelli FM, Dionisi-Vici C. Retinal degeneration. Ophthalmology. 2009;116:1593.

45. Mühling J, Dehne MG, Fuchs M, Sablotzki A, Weiss S, Spatz J, et al. Conscientious metabolic monitoring on a patient with hyperornithinemiahyperammonemia-homocitrullinuria $(\mathrm{HHH})$ syndrome undergoing anaesthesia. Amino Acids. 2001;21:303-18.

46. Gallagher AC, Pike M, Standing S. HHH syndrome associated with callosal agenesis and disordered neuronal migration. Dev Med Child Neurol. 2001:43:430-1.
47. Tsujino S, Miyamoto T, Kanazawa N. [Molecular genetic studies of mitochondrial ornithine transporter deficiency ( $\mathrm{HHH}$ syndrome)]. Nihon Rinsho. 2001;59:2278-84

48. Behulova D, Bzduch V, Skodova J, Fabricova K, Kolnikova M, Ponec J, et al. An atypical case of hyperornitinaemia-Hyperammonemia-homocitrullinuria (HHH) syndrome. J Inherit Metab Dis. 2001;24 suppl 1:44.

49. Miyamoto T, Kanazawa N, Hayakawa C, Tsujino S. A novel mutation, P126R, in a Japanese patient with HHH syndrome. Pediatr Neurol. 2002;26:65-7.

50. Korman SH, Kanazawa N, Abu-Libdeh B, Gutman A, Tsujino S. Hyperornithinemia, hyperammonemia, and homocitrullinuria syndrome with evidence of mitochondrial dysfunction due to a novel SLC25A15 (ORNT1) gene mutation in a Palestinian family. J Neurol Sci. 2004;218:53-8.

51. Torisu H, Kira R, Kanazawa N, Takemoto M, Sanefuji M, Sakai Y, et al. A novel R275X mutation of the SLC25A15 gene in a Japanese patient with the $\mathrm{HHH}$ syndrome. Brain Dev. 2006;28:332-5

52. Fecarotta S, Parenti G, Vajro P, Zuppaldi A, Della Casa R, Carbone MT, et al. $\mathrm{HHH}$ syndrome (hyperornithinaemia, hyperammonaemia, homocitrullinuria), with fulminant hepatitis-like presentation. J Inherit Metab Dis. 2006;29:186-9.

53. Camacho JA, Mardach R, Rioseco-Camacho N, Ruiz-Pesini E, Derbeneva O, Andrade D, et al. Clinical and functional characterization of a human ORNT1 mutation (T32R) in the hyperornithinemia-hyperammonemiahomocitrullinuria $(\mathrm{HHH})$ syndrome. Pediatr Res. 2006:60:423-9.

54. Verloo P, De Meirleir L, Van Hove J, Van Biervliet S, Van Winckel M. Liver transplantation cures biochemical defect in a boy with hyperammonemiahyperornithinaemia-homocitrullinuria (HHH Syndrome). J Inherit Metab Dis. 2007:30 Suppl 1:85.

55. Mhanni AA, Chan A, Collison M, Seifert B, Lehotay DC, Sokoro A, et al. Hyperornithinemia-hyperammonemia-homocitrullinuria syndrome $(\mathrm{HHH})$ presenting with acute fulminant hepatic failure. J Pediatr Gastroenterol Nutr. 2008;46:312-5

56. Al-Hassnan ZN, Rashed MS, Al-Dirbashi OY, Patay Z, Rahbeeni Z, Abu-Amero KK. Hyperornithinemia-hyperammonemia-homocitrullinuria syndrome with stroke-like imaging presentation: clinical, biochemical and molecular analysis. J Neurol Sci. 2008;264:187-94.

57. Tessa A, Fiermonte G, Dionisi-Vici C, Paradies E, Baumgartner MR, Chien YH, et al. Identification of novel mutations in the SLC25A15 gene in hyperornithinemia-hyperammonemia-homocitrullinuria $(\mathrm{HHH})$ syndrome: a clinical, molecular, and functional study. Hum Mutat. 2009;30:741-8.

58. Tezcan K, Louie KT, Qu Y, Velasquez J, Zaldivar F, Rioseco-Camacho N, et al. Adult-onset presentation of a hyperornithinemia-hyperammonemiahomocitrullinuria patient without prior history of neurological complications. J Inherit Metab Dis Rep. 2012;3:97-102.

59. Filosto M, Alberici A, Tessa A, Padovani A, Santorelli FM. Hyperornithinemiahyperammonemia-homocitrullinuria $(\mathrm{HHH})$ syndrome in adulthood: a rare recognizable condition. Neurol Sci. 2013;34:1699-701.

60. Ersoy Tunalı N, Marobbio CM, Tiryakioğlu NO, Punzi G, Saygılı SK, Onal H, et al. A novel mutation in the SLC25A15 gene in a Turkish patient with $\mathrm{HHH}$ syndrome: functional analysis of the mutant protein. Mol Genet Metab. 2014;112:25-9.

61. Lee HH, Poon KH, Lai CK, Au KM, Siu TS, Lai JP, et al. Hyperornithinaemiahyperammonaemia-homocitrullinuria syndrome: a treatable genetic liver disease warranting urgent diagnosis. Hong Kong Med J. 2014;20:63-6.

62. Summar ML, Koelker S, Freedenberg D, Le Mons C, Haberle J, Lee HS, et al. The incidence of urea cycle disorders. Mol Genet Metab. 2013;110:179-80.

63. Dionisi-Vici C, Rizzo C, Burlina AB, Caruso U, Sabetta G, Uziel G, et al. Inborn errors of metabolism in the Italian pediatric population: a national retrospective survey. J Pediatr. 2002;140:321-7.

64. Valle D, Simell O. The hyperornithinemias. In: Scriver CR, Beaudet AL, Sly WS, Valle D, editors. The metabolic and molecular bases of inherited diseases. New York: McGraw-Hill; 2001. p. 1857-97.

65. Indiveri C, Tonazzi A, Palmieri F. Identification and purification of the ornithine/citrulline carrier from rat liver mitochondria. Eur J Biochem. 1992;207:449-54

66. Palmieri F. The mitochondrial transporter family (SLC25): physiological and pathological implications. Pflugers Arch. 2004;447:689-709.

67. Indiveri C, Tonazzi A, Stipani I, Palmieri F. The purified and reconstituted ornithine/citrulline carrier from rat liver mitochondria catalyses a second transport mode: ornithine+/H+ exchange. Biochem J. 1999;341:705-11.

68. Fiermonte G, Dolce V, David L, Santorelli FM, Dionisi-Vici C, Palmieri F, et al. The mitochondrial ornithine transporter. Bacterial expression, reconstitution, 
functional characterization, and tissue distribution of two human isoforms. J Biol Chem. 2003;278:32778-83.

69. Camacho JA, Rioseco-Camacho N. The human and mouse SLC25A29 mitochondrial transporters rescue the deficient ornithine metabolism in fibroblasts of patients with the hyperornithinemia-hyperammonemiahomocitrullinuria $(\mathrm{HHH})$ syndrome. Pediatr Res. 2009:66:35-41.

70. Camacho JA, Rioseco-Camacho N, Andrade D, Porter J, Kong J. Cloning and characterization of human ORNT2: a second mitochondrial ornithine transporter that can rescue a defective ORNT1 in patients with the hyperornithinemia-hyperammonemia-homocitrullinuria syndrome, a urea cycle disorder. Mol Genet Metab. 2003;79:257-71.

71. Porcelli V, Fiermonte G, Longo A, Palmieri F. The human gene SLC25A29, of solute carrier family 25 , encodes a mitochondrial transporter of basic amino acids. J Biol Chem. 2014:289:13374-84.

72. Palmieri F. Mitochondrial transporters of the SLC25 family and associated diseases: a review. J Inherit Metab Dis. 2014;37:565-75.

73. Bachmann C. Inherited hyperammonemias. In: Blau N, Duran M, Blaskovic ME, Gibson KM, editors. Physician's guide to the laboratory diagnosis of metabolic diseases. Berlin: Springer; 2003. p. 261-76.

74. Boenzi S, Pastore A, Martinelli D, Goffredo BM, Boiani A, Rizzo C, et al. Creatine metabolism in urea cycle defects. J Inherit Metab Dis. 2012;35:647-53.

75. Sipilä I, Simell O, Arjomaa P. Gyrate atrophy of the choroid and retina with hyperornithinemia. Deficient formation of guanidinoacetic acid from arginine. J Clin Invest. 1980;66:684-7.

76. Valayannopoulos V, Boddaert N, Mention K, Touati G, Barbier V, Chabli A et al. Secondary creatine deficiency in ornithine delta-aminotransferase deficiency. Mol Genet Metab. 2009:97:109-13.

77. Braissant $\mathrm{O}$. Ammonia toxicity to the brain: effects on creatine metabolism and transport and protective roles of creatine. Mol Genet Metab. 2010;100 Suppl 1:S53-8.

78. Braissant $\mathrm{O}$, Henry $\mathrm{H}$, Villard AM, Zurich MG, Loup M, Eilers B, et al. Ammonium-induced impairment of axonal growth is prevented through glial creatine. J Neurosci. 2002;22:9810-20.

79. Viegas CM, Zanatta A, Knebel LA, Schuck PF, Tonin AM, Ferreira Gda C, et al. Experimental evidence that ornithine and homocitrulline disrupt energy metabolism in brain of young rats. Brain Res. 2009;1291:102-12.

80. Viegas CM, Busanello EN, Tonin AM, de Moura AP, Grings M, Ritter L, et al. Dual mechanism of brain damage induced in vivo by the major metabolites accumulating in hyperornithinemia-hyperammonemia-homocitrullinuria syndrome. Brain Res. 2011;1369:235-44.

81. Monné M, Miniero DV, Daddabbo L, Robinson AJ, Kunji ERS, Palmieri F. Substrate specificity of the two mitochondrial ornithine carriers can be swapped by single mutation in substrate binding site. J Biol Chem. 2012;287:7925-34.

82. Badizadegan K, Perez-Atayde AR. Focal glycogenosis of the liver in disorders of ureagenesis: its occurrence and diagnostic significance. Hepatology. 1997:26:365-73.

83. Grünewald S, Davison J, Martinelli D, Duran M, Dionisi-Vici C. Emergency diagnostic procedures and emergency treatment. In: Blau N, Duran M, Gibson KM, Dionisi-Vici C, editors. Physician's guide to the diagnosis, treatment, and follow-up of metabolic diseases. Berlin: Springer; 2014. p. 709-18.

84. van Karnebeek CD, Sly WS, Ross CJ, Salvarinova R, Yaplito-Lee J, Santra S, et al. Mitochondrial carbonic anhydrase VA deficiency resulting from CA5A alterations presents with hyperammonemia in early childhood. Am J Hum Genet. 2014;94:453-61.

85. Stockler S, Braissant O, Schulze A. Creatine disorders. In: Blau N, Duran M, Gibson KM, Dionisi-Vici C, editors. Physician's guide to the diagnosis, treatment, and follow-up of metabolic diseases. Berlin: Springer; 2014. p. $529-40$.

86. Cleary MA, Dorland L, de Koning TJ, Poll-The BT, Duran M, Mandell R, et al. Ornithine aminotransferase deficiency: diagnostic difficulties in neonatal presentation. J Inherit Metab Dis. 2005;28:673-9.

87. Palacín M, Bertran J, Chillarón J, Estévez R, Zorzano A. Lysinuric protein intolerance: mechanisms of pathophysiology. Mol Genet Metab. 2004;81 Suppl 1:S27-37.

88. Häberle J, Rubio V. Hyperammonemias and related disorders. In: Blau N, Duran M, Gibson KM, Dionisi-Vici C, editors. Physician's guide to the diagnosis, treatment, and follow-up of metabolic diseases. Berlin: Springer; 2014. p. 47-62.
89. Baranello G, Alfei E, Martinelli D, Rizzetto M, Cazzaniga F, Dionisi-Vici C, et al. Hyperargininemia: 7-month follow-up under sodium benzoate therapy in an Italian child presenting progressive spastic paraparesis, cognitive decline, and novel mutation in ARG1 gene. Pediatr Neurol. 2014;51:430-3.

90. Sokoro AA, Lepage J, Antonishyn N, McDonald R, Rockman-Greenberg C, Irvine J, et al. Diagnosis and high incidence of hyperornithinemiahyperammonemia-homocitrullinemia $(\mathrm{HHH})$ syndrome in northern Saskatchewan. J Inherit Metab Dis. 2010;33 Suppl 3:S275-81.

91. Marescau B, Lowenthal A, Terheggen HG, Esmans E, Alderweireldt F. Guanidino compounds in hyperargininemia. Adv Exp Med Biol. 1982;153:427-34

92. Deignan JL, De Deyn PP, Cederbaum SD, Fuchshuber A, Roth B, Gsell W, et al. Guanidino compound levels in blood, cerebrospinal fluid, and post-mortem brain material of patients with argininemia. Mol Genet Metab. 2010;100 Suppl 1:S31-6.

93. McCornico RS, Duckett WM, Wood PA. Persistent hyperammonemia in two related Morgan weanlings. J Vet Intern Med. 1997;11:264-6.

\section{Submit your next manuscript to BioMed Central and take full advantage of:}

- Convenient online submission

- Thorough peer review

- No space constraints or color figure charges

- Immediate publication on acceptance

- Inclusion in PubMed, CAS, Scopus and Google Scholar

- Research which is freely available for redistribution 